TAPROBANICA, ISSN 1800-427X. May, 2020. Vol. 09, No. 01: pp. 1-2.

(C) Research Center for Climate Change, University of Indonesia, Depok, Indonesia

www.taprobanica.org



\title{
The IUCN Red List and its role in data-driven conservation
}

\begin{abstract}
"When in America hundreds of thousands of acres of primeval forest are annually destroyed the conditions of life of a numerous fauna and flora must be thereby suddenly changed, leaving no choice but extermination" - Weissmann 1882
\end{abstract}

Since its creation in 1964, 112,432 species have had their risk of extinction assessed on the IUCN Red List, with a goal to have assessed at least 160,000 by the end of 2020 (IUCN 2020). It is the world's largest database of species-level conservation information, with each species evaluated against standardized, quantitative criteria to determine whether it should be recognized as being at risk of extinction. 2020 will be a milestone year for the Red List: with the completion of the first Global Reptile Assessment, for the first time every recognised species of terrestrial vertebrate (other than a number of recent descriptions) that is either extant or recently extinct will have an associated extinction risk assessment on the Red List.

Tabrobanica was founded on a vision of promoting scientific conservation, using the results of research on species' biology and populations to inform management and restoration efforts (Amarasinghe 2009). This ambition is firmly in line with the traditions of the Red List, which collects data on species' requirements and their current status from knowledgeable experts and applies a systematic approach to assigning Red List Categories.

In turn, the final assessments are widely used in scientific research, with IUCN (2020) describing "Guiding scientific research" as one of the Red List's primary uses. As well as providing the baseline data with which researchers can analyse variables that correlate with extinction risk, habitat preferences or specific threats, the Red List assessments capture important textual information that serve as a historical record of a species' abundance, distribution, known ecological tolerances and pressures at the time the assessment was conducted.

This is in many cases a challenging task, and reptiles are particularly poorly-known among vertebrate groups: Böhm et al. (2013) found that, based on a random sample of 1,500 reptiles globally, more than $20 \%$ were assessed as Data Deficient, while over $14 \%$ of described lizards are known only from their type localities (Meiri et al. 2018). These data gaps are of course not confined to reptiles, and may be even more acute for invertebrate groups, including those potentially at serious risk of extinction.

Even for well-known species, the most common condition used to judge whether a species is at risk of extinction rests on the $19^{\text {th }}$ Century logic I quoted at the start of this editorial: an assumption that as habitat is lost, so too are species. The wide availability of estimates of forest loss in particular in recent years has improved our ability to (at least crudely) infer rates of population decline from rates of habitat loss, but this remains an issue laden with coarse and not necessarily well-justified assumptions. For taxa inhabiting environments where the impacts of habitat degradation are less conspicuous than clearance of forest, such inferences remain fraught with additional assumptions. This reliance on surrogate measures, rather than an evaluation grounded in documented changes in the population status of the animals, plants or fungi themselves, is no fault of the Red List process but a constraint imposed by the quality of data available on most wild species. Direct impacts of environmental disturbance on animals' life histories, reproduction, disruption to a food chain, or population viability are very rarely understood (Milligan et al. 2009), and for the vast majority of species will be realistically impossible to obtain. 
This has serious practical implications when dealing with pressures such as climate change, potentially unsustainable harvesting of wildlife resources, or impacts of pollution or disease which may not directly correlate with a visible loss of habitat. It also hinders our understanding of the extent to which species can persist in degraded or secondary habitats, and - when aiming to restore species diversity, ecosystem function, or conserve specific species - which structural features of the environment and which ecological relationships are most important to preserve to achieve these goals. In this context, focused scientific research targeting species that have been identified as either threatened with near-future extinction (in the categories Vulnerable, Endangered or Critically Endangered) or Data Deficient is of vital importance for both informing future Red List assessments of these species and for directly aiding conservationists in managing these species through identifying priorities for their conservation. Given the enormity of the task ahead of us in terms of obtaining good data at the resolution necessary to best-inform conservation, it is imperative to have a mechanism to identify and focus that research on species at most risk of extinction. The best tool available to achieve that end is the IUCN Red List.

\section{Literature cited}

Amarasinghe, A.A.T. (2009). Editorial: An introduction to Taprobanica. Taprobanica, 1 (1): 1.

Böhm, M., B. Collen, J.E.M. Baillie, P. Bowles, J. Chanson et al. (2013). The conservation status of the world's reptiles. Biological Conservation, 157: 372-385.

IUCN (2020). The IUCN Red List of Threatened Species. Version 2019-3. https://www.iucnredlist.org

Meiri, S., A.M. Bauer, A. Allison, F. Castro-Herrera, L. Chirio et al. (2018). Extinct, obscure or imaginary: The lizard species with the smallest ranges. Diversity and Distributions, 24 (2): 262-273.

Milligan, S.R., W.V. Holt, and R. Lloyd (2009). Impacts of climate change and environmental factors on reproduction and development in wildlife. Philosophical Transactions of the Royal Society B: Biological Sciences, 364: 3313-3319.

Weissmann, A. (1882). Studies in the Theory of Descent: Sampson Low (London): 651 pp.

\section{Philip Bowles}

Coordinator

Snake \& Lizard Red List Authority

CI-IUCN Biodiversity Assessment Unit

1630, Connecticut Avenue, Suite 300

Washington DC 22202

USA

Deputy Editor: Taprobanica, the journal of Asian Biodiversity

February $04^{\text {th }}, 2020$ 